\title{
Extending Learning Beyond The Exam: Multiple-Choice Tests
}

\author{
Joann Bangs, College of St. Catherine
}

\begin{abstract}
In this paper I describe a method to help students go back and better understand material they got wrong on multiple-choice tests.
\end{abstract}

Keywords: assessment, multiple choice questions

have always used some multiple-choice questions when I test students in my introductory level courses.
I use these types of questions because they are an efficient way to see if students have an understanding
of the basic concepts in the course. A study by Becker and Watts (2001) shows that I am far from alone in this regard. They report that about $45 \%$ of course grades in introductory economics classes are determined by multiple-choice questions. Unfortunately I have often found myself frustrated by student performance on multiplechoice tests. In particular I am surprised at how often students repeat the same mistake when asked a similar multiple-choice question on a later test despite the fact that the students had been given an answer key for the multiple-choice questions. I wanted to find a way to help students learn from the mistakes they had made on my multiple-choice exams. My solution was to have students work through an exercise to evaluate the information present in both the correct choice and the incorrect choice they had made through an assignment that I refer to as 'explanations.'

A fair amount of research has been done on the use of multiple-choice questions both in general and specific to the field of economics. On the positive side, Buckles and Siegfried (2006) showed that a well written multiple-choice question can be used to evaluate up to level four of Bloom's taxonomy of educational achievement (analysis). However, those well constructed questions may pose a problem for the students that get them wrong. Butler et al (2006) show that when students cannot immediately identify the correct answer, they may spend time comparing the possible answers. While they are engaged in this process they may be building a relationship between incorrect answers and the concept being tested. The relationship can cause them to recall incorrect rather than correct answers in later testing situations. From my own experience, it seems that simply telling students the correct answer after the fact does not improve their ability to answer similar multiple-choice questions at a later date. It seems that more needs to be done to help students to learn from their mistakes rather than to remember their mistakes.

This assignment developed during my first year of teaching at the College of St. Catherine. I had several years experience in teaching principles courses, but it was my first experience in teaching principles to this particular group of students. As I was quite sure none of these students would have access to any exams I had given at other institutions, I constructed an exam that used only questions I had used before. To my dismay, my students at the College of St. Catherine performed much worse on this exam than I had seen in other institutions. This difference was most pronounced on the multiple-choice section of the test. As I faced the thought of walking into that room full of students to tell them that over one-third of the class had earned Ds or Fs on the exam, I knew I had to do something. I was confident that these students were capable of performing at a much higher level in this course. However I was very concerned that this negative experience of a poor performance on an exam would get in the way of helping these students to reach their potential.

I felt that I needed to convince these students that they should have done much better on the exam. I wanted them to sit down with their exams, their class notes and the textbook and work through the exam again. It 
seemed highly unlikely that my students would go through this process unless they were given a concrete incentive to do so. I worked to come up with an assignment that would turn this negative experience of a poor exam result into a positive learning experience. I gave the students the following assignment. I asked the students to take their exams home and use their class notes and textbooks to do two things for each of the multiple-choice questions they missed. I asked them to explain why the correct answer is correct and to explain why the answer they chose is incorrect. I made this assignment optional, but allowed students to earn back one point per missed multiple-choice question on their exam for each well done explanation. (The multiple-choice questions had been worth three points each on the original exam.) I was very pleased with the results. Many of the students chose to complete the explanations and doing so made a big change in atmosphere of the class. My fear that the exam would result in my having to teach a room full of disgruntled students for the rest of the semester was not realized. Many of the students noted in their explanations that they should have done much better on the exam than they did. Now rather than having the students continue to use the same study techniques that had failed them before, the students had an opportunity to see what they could have done differently in their studying. The assignment had helped them to learn how to learn economics.

It should be noted that the idea of having to explain the choices on a multiple-choice test is not new. Buckles and Siegfried (2006) mention a similar idea as a method to use multiple-choice tests to evaluate higher levels of learning. They suggest having students explain why the correct answer is correct and why each of the incorrect answers is incorrect to aid in assessing the higher level learning of the student. However to use this method on all multiple-choice questions on all tests would be too costly to me. For good or for bad, one of the reasons I use multiple-choice questions is to reduce grading time on exams. In contrast I have found that narrowing the assignment to only those multiple-choice questions that were missed and to explaining only the one incorrect choice the student made has made for a very manageable level of additional grading burden.

I was so pleased with the results from the first time I used this assignment that I have continued to use it for all multiple-choice questions on any test give in any course. I see clear benefits to the process as I grade the explanations. If students are unable to figure out why the right answer is right or why the answer they chose is wrong, I get a picture of what the source of the confusion is from each student by what they write in their explanations. This assignment gives me the opportunity to give students another push in the right direction. This process has given me the opportunity to take the summative evaluation of the exam and create an opportunity to turn that evaluation into a formative evaluation. Being able to get a picture of what is confusing to students has also helped my teaching. I have used that information to help me find better ways to teach the material to the students the next time.

Knowing that I found these assignments useful, I decided to find out what my students thought of them. During the fall semester of 2007 I surveyed my students to ask them their opinions on the multiple-choice explanation assignments. In this voluntary and anonymous survey (see Appendix 1 for a copy of the survey). I first asked the students to indicate if they chose to complete the multiple-choice explanations always, sometimes, rarely or never. Of the 46 students that completed the survey, 34 indicated that they always choose to complete the explanations, 10 indicated that they sometimes choose to complete the explanations and 2 indicated that they rarely choose to complete the explanations. None of the 46 students indicated that they never choose to complete the explanations.

For those students that at times chose not to complete the multiple-choice explanations, I asked them to tell me what factor was most important in their decision to not complete the assignment. Of the 12 students that at times chose not to complete the assignment, only 3 indicated that the small number of points they could earn prevented them from completing the assignment. Three others chose the 'other' category. Of these students, two indicated they did not have enough time to do the assignment. One indicated that she ${ }^{1}$ had missed class on the days that the topics tested on the questions she missed were covered and felt she was unable to complete the assignment.

\footnotetext{
${ }^{1}$ The College of St. Catherine offers baccalaureate level classes to women only.
} 
The remaining 6 students all indicated that they were planning to retake the exam. ${ }^{2}$ I do try to encourage students to complete the explanations even if they are planning to retake the exam. I try to convince them that doing the explanations is a good way to prepare for the retake. However, it seems that I am not entirely successful at convincing students of this idea. In contrast other students indicated later in the survey that they did find the assignment helpful in preparing for the retake of the exam.

I next asked all the students to indicate what they liked best about the assignment. Two main themes came out of this question: earning more points and better understanding the material. Of the 12 students that sometimes chose not to complete the assignment, 7 described only the opportunity to earn more points. Two of these students indicated that liked to opportunity to better understand the material. The remaining 3 students described both the opportunity to earn more points and the opportunity to better understand the material. Of the 34 students that always chose to complete the assignment, 8 described only the opportunity to earn more points. Ten of these students indicated that the appreciated the opportunity to better understand the material. The remaining 16 described both the opportunity to earn more points and the opportunity to better understand the material.

Finally I asked students to tell me whether or not they felt the multiple-choice explanations helped them to better understand the material. Many of the students had already mentioned this opportunity as a reason why they liked the assignment. Many reiterated what they had written earlier. Looking at the 12 students that sometimes chose not to complete the assignment, 9 indicated the assignment did help them to better understand the material and 3 indicated mixed feelings on this issue. None of the students indicated that the assignment did not help them to better understand the material. Looking at the 34 students that always completed the assignment 30 indicated that the assignment did help them to better understand the material and 4 indicated mixed feelings on this issue. Again, none of the students indicated that the assignment did not help them to better understand the material. ${ }^{3}$

Overall I think the results of the survey show that the students also see a value to this assignment. Many of the comments the students wrote allude to the fact that a summative evaluation does not encourage students to go back and work again on the material they had trouble with. However, by offering the opportunity to change the summative evaluation of the exam into a formative evaluation does give the students the incentive to keep working and learning beyond the date of the exam.

\section{BIOGRAPHY}

Joann Bangs has a B.S. in Economics from the University of Wisconsin-Madison, and both an M.A. and a Ph.D. in Economics from the University of Minnesota. She is currently an assistant professor in the Department of Economics at the College of St. Catherine. Her current research interests include fair trade programs, the relationship between free trade agreements and the environment and economics education. She has presented this work at international conferences.

\section{REFERENCES}

1. Becker, W.E. and M. Watts, (2001), Teaching Methods in the U.S. Undergraduate Economics Courses, Journal of Economic Education 32(3), pp. 269-79.

2. Buckles, S. and J.J. Siegfried, (2006), Using Multiple-Choice Questions to Evaluate In-Depth Learning of Economics, Journal of Economic Education 37(1), pp. 48-57.

3. Butler, A.C., E.J. Marsh, M.K. Goode and H.L. Roediger, III, (2006), When Additional Multiple-Choice Lures Aid Versus Hinder Later Memory, Applied Cognitive Psychology 20, pp. 941-56.

4. $\quad$ Pregent, R., (2004), Charting Your Course: How to Prepare to Teach More Effectively, Madison, Magna Publications Inc.

\footnotetext{
${ }^{2}$ In my introductory level courses I allow students the option of doing a retake for one of the exams. Students can choose to have their original test score replaced by the score on a new test on the same material given at the end of the semester.

${ }^{3}$ See Appendix 2 for selected quotes from the surveys.
} 


\section{APPENDIX 1}

\section{Survey On Explanations}

I would like to get some feedback from all of you on how you feel the multiple-choice explanations assignment works for you. This survey is voluntary. If you do not wish to participate you may simply leave this form blank. This survey is anonymous. Please do NOT put your name on this survey. If there are any questions that you would prefer not to answer, please leave those questions blank.

As you answer these questions, please consider both this course and all other courses you have taken with me.

1) How often have you chosen to complete the multiple-choice explanations? Please circle your response.

\section{ALWAYS SOMETIMES RARELY NEVER}

2) What is the most important factor that prevents you from completing the multiple-choice explanations? Please check only one response.

Too much time to complete the work
Not enough points available
Planning on retaking that exam
Other-please specify:
Does not apply. I always chose to complete the multiple-choice
explanations

If you have chosen to complete multiple-choice explanations, please continue to the next question.

If you have never chosen to complete the multiple-choice explanations, you are finished with this survey.

3) What do you like best about the multiple-choice explanations?

4) Do you feel like the multiple-choice explanations help you better understand the material? Why or why not? 


\section{APPENDIX 2}

\section{Selected Quotes From The Student Surveys}

Question 3: What do you like best about the multiple-choice explanations?

I get to learn why my answer was wrong and why the correct one is correct. Most of the time I haven't just guessed out of nowhere. I really thought my answer was right so I get to change my way of thinking about the subject.

That it allows me to receive points on problems that I should have gotten right. I always have the "Duh" moment when I read the ones I have got wrong. It also helps me understand why.

Gives me a chance to at least partially correct stupid mistakes I make on tests.

Earning back points and helpful for retaking the test.

Getting my grade up. It's something that does not take much time that can help your grade.

I can focus on the essay questions more on the test day, start with them, and know that I could get points back from the multiple-choice questions I get wrong by possibly rushing through them when I don't have enough time.

I like that it forces me to go back and look up the answers. I wouldn't do that if it wasn't any option for extra points.

I like the opportunity to earn back points and the chance to show that I understand the material.

I like the chance to get points back \& I like figuring out what I didn't understand so that if I were to retake the exam I know what I didn't get before.

It gives me the opportunity to teach myself the material that I obviously don't have down as well as earn back points.

It gives you a chance to go back \& review your mistake and really think about why the correct answer is right. It's really nice to be given partial credit for understanding the correct answer rather than losing all points for an incorrect answer.

A chance to understand what I got wrong $\&$ why $\rightarrow$ it's not as helpful when professors just tell me the answer really helps to look it up on my own - like I'm learning from my mistakes. The extra points added back are nice too.

I like them because after reviewing my mistakes; I learn exactly why they were wrong answers. I really like the explanations, they're very efficient.

Question 4: Do you feel like the multiple-choice explanations help you better understand the material? Why or why not?

Yes. I have to reason through it more so I can explain myself, which I think not only helps me understand it better, but also remember it better.

To an extent. However, I would say it's more likely that I will not better understand the material ... just look at the book/notes for the correct answer.

Yes \& no. Sometimes it helps to clarify an idea or the material - other times I made a stupid/simple mistake \& it doesn't change my knowledge level, it just makes me think to slow down \& reread questions for the next exam. Out of the 2 multiple-choice I got wrong in this last exam one I truly did not understand until after writing the explanation, \& the other was a simple mistake. 
They do help sometimes, other times I run into the same problems understanding the material I had before.

Yes. Often times after a test people just look and see what they got as a grade and don't look back to see why. I think it helps understand and because you get points for doing it you want to.

Yes. It helps me to realize what I was thinking when I circled the letter. Most of the time I realize I just circled the wrong letter, but it still helps me learn more.

Yes, because I go back and relearn something I missed. I think it is a great tool. Plus we don't have to waste time in class going over each one together - that can be tedious.

Yes, after you get the response back from the explanations you know if you really do understand the information or not.

I do feel that the explanations help me understand the material better because it "forces" me to look back at the notes and books for the right answer. (Something I should, but rarely do, for tests.)

Yes, you have to go look back at your notes \& the book to see what you did wrong, \& you have to write about it which better helps me learn.

Yes but I have gotten frustrated because I thought I correctly redid and explained the question \& answer \& did not receive full points.

Yes - it is kind of an incentive to go back and review the material, learn from your mistakes, and retain that info better.

Yes, they do. They really do.

Yes. It forces me to really think about my answer and how to reach the answer. I honestly probably wouldn't think that hard about it if I didn't do them. 